\title{
Índices de nitrogênio e modelo para prognosticar a produção de tubérculos de batata ${ }^{1}$
}

\author{
Carla do Carmo Milagres.", Paulo Cezar Rezende Fontes ${ }^{2}$, Murilo Vargas da Silveira $^{3}$, \\ Marialva Alvarenga Moreira², Iza Paula de Carvalho Lopes ${ }^{2}$
}

$10.1590 / 0034-737 X 201865030006$

\begin{abstract}
RESUMO
A utilização de índices constitui ferramenta prática e importante para o manejo da adubação nitrogenada, na cultura da batata e, ainda, pode prognosticar a produtividade de tubérculos. Assim, objetivou-se avaliar o efeito do parcelamento do fertilizante nitrogenado sobre índices de nitrogênio $(\mathrm{N})$ em plantas de batata, bem como estabelecer um modelo para o prognóstico da produtividade de tubérculos. Foram utilizados os cultivares Ágata e Asterix em dois experimentos independentes. Os tratamentos foram: T1 - controle, sem adubação nitrogenada, T2- 50\% da dose no plantio + 50\% aos 22 dias após a emergência (DAE) e T3 - dose única no plantio. Foi utilizada a ureia como fonte de $\mathrm{N}$ e a dose total aplicada foi de $220 \mathrm{~kg} \mathrm{ha}^{-1} \mathrm{de} \mathrm{N}$. Os índices avaliados foram: clorofila (CHL), flavonóis (FLV), balanço de N (NBI), determinados, com o Dualex e SPAD, na quarta folha completamente desenvolvida, aos 10, 21, 34, 48, 62 e 76 DAE. As doses e o parcelamento do N interferiram nos índices avaliados, sendo que os valores de SPAD, CHL e NBI decresceram com a idade da planta, enquanto houve aumento dos valores de FLV, para ambos os cultivares. O índice CHLé o mais indicado para estimar indiretamente o teor de nitrato na seiva do pecíolo, o teor de $\mathrm{N}$ na matéria seca e a quantidade de $\mathrm{N}$ acumulada na quarta folha. Tanto o índice SPAD quanto o índice CHL podem prognosticar a produtividade final de tubérculos de batata e foi estabelecido um modelo utilizando esses índices.
\end{abstract}

Palavras-chave: Solanum tuberosum L.; SPAD; Dualex; Asterix; Ágata

\section{ABSTRACT}

\section{Nitrogen indexes and model to prognostic the potato tubers production}

The use of indexes is a practical and important tool for nitrogen fertilization management on potato crop and can be used for the prognosis of tuber yield. Thus, this study aimed to determine the effect of splitting nitrogen fertilizer on nitrogen indexes, as well as to establish a model for the prognosis of tuber yield. The Agate and Asterix cultivars were used in two independent experiments. The treatments consisted of: $\mathrm{T} 1$ - control without $\mathrm{N}$ fertilization; $\mathrm{T} 2-50 \%$ of $\mathrm{N}$ dose at planting and $50 \%$ of $\mathrm{N}$ dose at 22 days after plant emergence (DAE); and $\mathrm{T} 3-100 \%$ of $\mathrm{N}$ dose at planting. Urea was used as source of $\mathrm{N}$ and the total dose applied was $220 \mathrm{~kg} \mathrm{ha}^{-1}$ of $\mathrm{N}$. The indexes evaluated were: chlorophyll (CHL), flavonol (FLV), nitrogen balance (NBI), evaluated with Dualex, and SPAD, determined in the fourth fully developed leaf at 10, 21, 34, 48, 62, and 76 DAE. Dose and N splitting interfered on the evaluated indexes, and the values of SPAD, CHL, and NBI decreased with increasing in plant age, while the FLV increased for both cultivars. The CHL index was the most suitable to indirectly estimate the petiole sap nitrate content, the $\mathrm{N}$ content in the dry matter, and the $\mathrm{N}$ accumulated in the fourth leaf. Both indexes, SPAD and CHL, can be used for the prognosis of the final potato tuber yield, and a model was established using these indexes.

Keywords: Solanum tuberosum L; SPAD; Dualex; Asterix; Ágata.

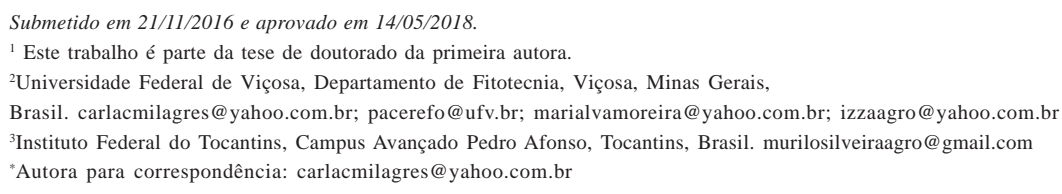




\section{INTRODUÇÃO}

A batata (Solanum tuberosum L.), um dos vegetais mais consumidos na dieta da população brasileira, apresenta elevado potencial produtivo, especialmente quando a cultura é adequadamente fertilizada com nitrogênio (N). A falta ou excesso desse nutriente são prejudiciais à cultura, ao produtor e ao meio ambiente, tornando desejável o manejo adequado do $\mathrm{N}$ na cultura.

$\mathrm{O}$ parcelamento do fertilizante nitrogenado tem sido indicado como uma das práticas adequadas de seu manejo, principalmente pela redução da probabilidade de perdas por lixiviação. Há estudos indicando que, em determinadas situações, a aplicação do fertilizante nitrogenado em duas vezes é mais eficiente do que a aplicação total no plantio, pois favorece a absorção do nutriente e aumenta o peso do tubérculo e, consequentemente, a produção (Cardoso et al., 2007).

Como a análise do solo ainda não é comum para o $\mathrm{N}$, tem sido utilizada a análise da planta para indicar o parcelamento da dose de N, aplicando-se o princípio da "adubação quando necessária" (Schepers et al., 1992). Neste caso, a resposta deve ser dada pela planta, por via de avaliação do estado de N (Fontes, 2011).

Índices precoces obtidos por medidas indiretas e rápidas para se avaliar o estado de $\mathrm{N}$ da planta, em tempo real, têm sido propostos pelas análises de índices de flavonóis e de clorofilas das folhas, utilizando-se diversos instrumentos (Fontes, 2016). Os flavonoides são metabólitos secundários da classe dos polifenóis, gerados quando as plantas estão sob deficiência de N (Demotes-Mainard et al., 2008).

O SPAD é um dos instrumentos mais utilizados em estudos de determinação do estado de $\mathrm{N}$ na planta, em tempo real (Coelho et al., 2012b; Zakeri et al., 2015; Zheng et al., 2015; Saravia et al., 2016). Outro instrumento também possível de ser utilizado na determinação do estado de N na planta é o Dualex, que, por meio de fluorescência da clorofila, propicia os índices de clorofila (CHL), o índice de flavonóis (FLV) e o índice de balanço de nitrogênio (NBI) (Coelho et al., 2012a; Muñoz-Huerta et al., 2013). Quase sempre, com o aumento da adubação nitrogenada, aumenta-se o teor de clorofila e diminui-se o teor de polifenóis nas folhas (Muñoz-Huerta et al., 2013).

Concomitantemente ao interesse em avaliar precocemente o estado nutricional da planta, em consonância com a agricultura de precisão ou com a prescrição e aplicação simultâneas do N, tem aumentado o interesse em prognosticar a produtividade das culturas por método rápido, fácil e, principalmente, em tempo real.

Assim, para prognosticar a produtividade de tubérculos de batata foi indicada a possibilidade de utilização da leitura SPAD e de índices biométricos (Coelho et al., 2010), em leitura realizada imediatamente antes da amontoa. Entretanto, não foram encontradas referências sobre a utilização da leitura SPAD, em diferentes épocas do ciclo da planta, como índice de prognóstico da produtividade de tubérculos de batata. Também, não foram encontradas referências sobre a utilização da leitura Dualex, como índice de prognóstico da produtividade de tubérculos de batata.

É sabido que vários fatores podem interferir no valor de um índice medido na folha (Fontes, 2001) e que a cor verde da folha é mais influenciada pela variação entre cultivares do que pela fertilização nitrogenada (Giletto et al., 2006). É escassa a informação sobre o efeito do parcelamento do fertilizante nitrogenado, em interação com a idade da planta e cultivar, sobre índices de $\mathrm{N}$ medidos pelos equipamentos SPAD e Dualex.

O objetivo deste trabalho foi avaliar o efeito do parcelamento do $\mathrm{N}$ sobre índices relacionados com a nutrição nitrogenada de batata, medidos pelos equipamentos SPAD e Dualex, em diferentes idades da planta, além de estabelecer modelo para o prognóstico da produtividade de tubérculos, ao longo do desenvolvimento dos cultivares de batata Ágata e Asterix.

\section{MATERIAL E MÉTODOS}

Foram instalados, simultaneamente, dois experimentos no campo, conduzidos entre os meses de junho e outubro de 2013. O plantio foi realizado no dia 20 de junho, na Horta Experimental do Departamento de Fitotecnia (DFT) da Universidade Federal de Viçosa (UFV), em solo classificado como Argissolo Vermelho-Amarelo câmbico. As características do solo, na camada de 0-20 cm de profundidade, amostrado antes da instalação dos experimentos, apresentavam $\mathrm{pH}$ (em água) $=5,3 ; \mathrm{P}=13,6 \mathrm{mg} \mathrm{dm}^{-3} ; \mathrm{K}$ $=38 \mathrm{mg} \mathrm{dm}{ }^{-3} ; \mathrm{Ca}^{2+}=2,6 \mathrm{cmolc} \mathrm{dm}^{-3} ; \mathrm{Mg}^{2+}=0,7 \mathrm{cmolc} \mathrm{dm}^{-}$ 3; $\mathrm{Al}^{3+}=0,0 \mathrm{cmolc} \mathrm{dm}^{-3} ; \mathrm{H}+\mathrm{Al}=2,97 \mathrm{cmolc} \mathrm{dm}^{-3} ; \mathrm{P}-\mathrm{rem}=$ $33,6 \mathrm{mg} \mathrm{L}^{-1} ; \mathrm{CTC}=6,37 \mathrm{cmolc} \mathrm{dm}^{-3} \mathrm{e} \mathrm{V}=53 \%$.

Cada experimento correspondeu a um cultivar de batata (Solanum tuberosum L.): Ágata e Asterix. Em cada experimento, foram avaliados três modos de parcelar a dose de $220 \mathrm{~kg} \mathrm{ha}^{-1}$ de N, como ureia (44\% de N). Os tratamentos foram: T1 (controle, sem aplicação de N), T2 (50\% da dose no plantio $+50 \%$ aos 22 dias após a emergência (DAE)) e T3 (unicamente no plantio). Durante o período experimental foram realizadas cinco e seis avaliações para os cultivares Ágata e Asterix, respectivamente. Os experimentos foram instalados no delineamento em blocos casualizados, no esquema fatorial 3 x 7, para o cultivar Ágata, e 3 x 8, para o cultivar Asterix (modo de aplicação x época de avaliação), com três repetições.

No momento do plantio, além da correspondente dose de $\mathrm{N}$, foram adicionadas as doses dos demais fertilizan- 
tes, expressas em $\mathrm{kg} \mathrm{ha}^{-1}$, aplicadas no sulco de plantio: 384 de cloreto de potássio $\left(60 \%\right.$ de $\left.\mathrm{K}_{2} \mathrm{O}\right) ; 1.800$ de superfosfato simples $\left(18 \%\right.$ de $\left.\mathrm{P}_{2} \mathrm{O}_{5}\right) ; 200$ de sulfato de magnésio (10\% de $\mathrm{Mg}$ ); 10 de bórax (10\% de B); 10 de sulfato de zinco (20\% de Zn); 10 de sulfato de cobre (24\% de $\mathrm{Cu}$ ) e 0,5 de molibdato de sódio (39\% de Mo).

O material de propagação foram tubérculos sementes certificados, devidamente uniformizados e brotados naturalmente, adquiridos de firma comercial produtora de sementes, com massa média de $70 \mathrm{~g}$ por tubérculo. A amontoa foi realizada aos $22 \mathrm{DAE}$.

Cada parcela foi constituída de 16 plantas, distribuídas em quatro linhas, espaçadas de $0,75 \mathrm{~m}$ entre fileiras e $0,25 \mathrm{~m}$ entre plantas, com dimensões de 1,0 m de comprimento x 3,0 m de largura e ocupando a área total de 3,0 $\mathrm{m}^{2}$. As quatro plantas centrais foram consideradas úteis e as restantes foram consideradas bordaduras.

Aos 10, 20, 34, 48, 62 e 76 DAE foram avaliados, com o medidor Dualex, os índices de CHL, FLV e NBI, na folha completamente desenvolvida (quarta folha), como sugerido por diversos autores (Li et al., 2012). Adicionalmente, nas mesmas datas e folhas foram medidos o índice SPAD; o teor de ${\mathrm{N}-\mathrm{NO}_{3}}_{3}$ da seiva do pecíolo (TNSP); o teor de $\mathrm{N}$ da matéria seca e o conteúdo de $\mathrm{N}$ acumulado (QNA) na quarta folha. A solução extraída do pecíolo das folhas, apesar de ser denominada teor de nitrato da seiva do pecíolo (TNSP), é constituída de seiva bruta, seiva elaborada e constituintes (apoplasto, citosol e água vacuolar).

Como o parcelamento da dose foi feito aos 21 DAE, os resultados das avaliações efetuadas nas duas primeiras amostragens foram utilizados para avaliar o efeito de dose e, os demais resultados, para avaliar o efeito do parcelamento. A colheita final de todos os tubérculos da parcela foi realizada aos 90 DAE, para Ágata, e aos 102 DAE, para Asterix, sendo imediatamente pesados e obtida a produção total de tubérculos (dados não apresentados).

Os dados foram submetidos à análise de variância, de regressão e de correlação. Para cada época de amostragem, efetuou-se a análise de correlação linear simples (r), a 5 e $1 \%$ de probabilidade, entre os valores dos índices determinados na planta com a produção total de tubérculos. Em seguida, com as correlações significativas, foram ajustadas equações de regressão linear simples, tendo o valor da massa fresca de tubérculos como a variável dependente e, o valor de cada índice, como a variável independente. Para a execução das análises foi utilizado o sistema SAS (2002).

\section{RESULTADOS E DISCUSSÃO}

\section{Efeitos da Dose de N e da Idade das Plantas}

Os valores observados dos índices SPAD, CHL, FLV e NBI, em função da dose de N (0, 110 e $\left.220 \mathrm{~kg} \mathrm{ha}^{-1}\right)$, nas avaliações efetuadas em diferentes idades da planta (10 e 21 DAE), nos dois cultivares, Ágata e Asterix, estão mostrados na Tabela 1. Esses índices, em ambos os cultivares, foram significativamente influenciados por dose de $\mathrm{N}$, idade da planta e pela interação entre ambos.

Assim, mesmo precocemente, aos 10 e 21 DAE, houve resposta dos índices medidos, na planta, à dose de $\mathrm{N}$, sendo que os valores dos índices SPAD, CHL e NBI decresceram com a idade da planta e o oposto ocorreu com o índice FLV, para ambos os cultivares (Figuras 1 e 2).

Durante o ciclo da cultura muitos fatores podem interferir na mobilização do $\mathrm{N}$ na planta, dentre eles a duração do ciclo. Ágata apresenta ciclo precoce e Asterix ciclo médio-tardio. De acordo com Coelho et al. (2012b), a diferença pode ser explicada aparentemente pelo maior valor SPAD para a Ágata, 0,4054 SPAD unidade $\mathrm{dia}^{-1}$, comparado com 0,1551 unidade $\mathrm{dia}^{-1}$ do cultivar Asterix. Segundo esses autores, o aumento de doses de $\mathrm{N}$ resultou em aumento significativo da leitura SPAD e redução desta em relação aos dias após a emergência, para ambos os cultivares. Aumento da leitura SPAD, em batata com o aumento na dose de N, também foi relatado por outros autores (Gil et al., 2002; Coelho et al., 2010).

A diminuição do índice SPAD aos 21 DAE pode ter sido causada pela remobilização de $\mathrm{N}$ dentro da planta e isso pode ser observado, ocorrendo de forma mais acentuada, nos tratamentos que receberam menores doses de $\mathrm{N}$, como no cultivar Asterix. A redução do teor de $\mathrm{N}$ foliar com a idade da planta pode ser explicada por mecanismos que envolvem absorção de $\mathrm{N}$, acumulação e distribuição no interior da planta, bem como o seu desenvolvimento (Fontes, 2001). Porém, o mesmo fato não foi observado para o cultivar Ágata e isso pode estar relacionado com a eficiência na utilização de $\mathrm{N}$ pelo cultivar e pela diferença de ciclo das culturas.

Em Ágata, média e alta disponibilidade de N proporcionaram valores semelhantes de CHL enquanto, em Asterix, o valor de CHL foi maior em alta disponibilidade de N. Na literatura são encontrados trabalhos em que os índices de CHL e NBI, em batata, aumentaram linearmente com o aumento da dose (Coelho et al., 2012a).

O índice FLV está relacionado com a concentração de flavonoides na folha, podendo variar de 0 a 3,5 (Fontes, 2011). Quando há limitação de N, ocorre estresse nas plantas, ocasionando aumento do índice de FLV. Neste trabalho, o índice FLV decresceu com o aumento da dose de N, concordando com os resultados de Coelho et al. (2012a). Decréscimos no teor de FLV, determinado com o Dualex, com o aumento das doses de $\mathrm{N}$, também foram verificados para trigo (Tremblay et al., 2010), milho (Huan et al., 2010) e brócolis (Fortier et al., 2010). 
Em suma, os índices CHL e NBI, determinados com o medidor Dualex, aos 21 DAE, aumentaram com o aumento da disponibilidade de N, enquanto o índice FLV decresceu. Esses dados concordam com aqueles encontrados por Coelho et al. (2012a).

A relação entre os índices SPAD, CHL, FLV e NBI com o estado de $\mathrm{N}$ da planta, representada pelo teor de $\mathrm{N}$ da seiva do pecíolo (TNSP), o teor de $\mathrm{N}$ da matéria seca (TNMS) e a quantidade de $\mathrm{N}$ acumulada na matéria seca (QNA) da quarta folha de batata, para os dois cultivares, encontra-se na Tabela 2. É sabido que a relação entre a leitura SPAD e o teor de $\mathrm{N}$ da folha pode ser afetado por vários fatores, como características das folhas, estado hídrico e condições ambientais, como a radiação fotossinteticamente ativa e a hora do dia (Xiong et al., 2015). É sabido que a absorção do fóton depende da distribuição da clorofila na folha que é determinada pela organizaçao estrutural do grana dentro do cloroplasto, do cloroplasto dentro da célula e da célula nas camadas do tecido. Existem estudos mostrando que a reação da folha à mudança ambiental da luz é devida à movimentação dos cloroplastos e a seu rearranjo nas células da planta (Baránková et al., 2016).

Houve correlação linear positiva e significativa para o índice SPAD e as características TNMS, QNA aos 10 DAE, para ambos os cultivares, e correlação com as características TNSP, TNMS e QNA aos 21 DAE, somente para Asterix.

O índice significativo, comum aos dois cultivares, nas duas épocas de avaliação, para estimar as características representativas do estado de N, foi o CHL (Tabela 2). O índice FLV apresentou correlação negativa e significativa com TNSP e TNMS do cultivar Ágata, aos 21 DAE, e com o QNA do cultivar Asterix, aos 10 e 21 DAE. O índice NBI apresentou correlação positiva e significativa para TNSP e TNMS, aos 10 DAE, e TNMS e QNA, aos 21 DAE, para o cultivar Ágata, e para todas as características avaliadas nas duas épocas de avaliação, para o cultivar Asterix. O TNMS da folha é uma característica relativa, isto é, massa de $\mathrm{N}$ por unidade de massa da matéria seca. Por outro lado, QNA é uma característica absoluta, isto é quantidade de $\mathrm{N}$ na planta.

O teor de clorofila da folha está relacionado com o estado de $\mathrm{N}$ da planta. Correlação positiva entre a adição de $\mathrm{N}$ e aumento do teor de clorofila da folha da batata foi obtida por Gil et al. (2002), Coelho et al. (2010; 2012a). Esses últimos autores mostraram haver correlação linear positiva e significativa entre os índices CHL e NBI, e negativa entre o FLV e o teor de $\mathrm{N}$ determinado na quarta folha, confirmando os resultados encontrados por Cartelat et al. (2005).

Tabela 1: Valores médios dos índices SPAD, clorofila (CHL), índice balanço de N (NBI) e flavonoides (FLV), em função das doses de nitrogênio $\left(0,110\right.$ e $\left.220 \mathrm{~kg} \mathrm{ha}^{-1}\right)$, em duas idades da planta de batata (10 e $\left.21 \mathrm{DAE}\right)$, cultivares Ágata e Asterix

\begin{tabular}{|c|c|c|c|c|}
\hline & \multicolumn{4}{|c|}{ Dias após a emergência (DAE) } \\
\hline & 10 & 21 & 10 & 21 \\
\hline & \multicolumn{2}{|c|}{ Ágata } & \multicolumn{2}{|c|}{ Asterix } \\
\hline & \multicolumn{2}{|c|}{ SPAD } & \multicolumn{2}{|c|}{ SPAD } \\
\hline \multicolumn{5}{|l|}{ Dose } \\
\hline 0 & 46,43 & 43,95 & 44,45 & 36,53 \\
\hline 110 & 47,80 & 43,23 & 48,00 & 42,17 \\
\hline \multirow[t]{2}{*}{220} & 56,30 & 46,50 & 46,83 & 46,35 \\
\hline & \multicolumn{2}{|c|}{ CHL } & \multicolumn{2}{|c|}{$\mathrm{CHL}$} \\
\hline \multicolumn{5}{|l|}{ Dose } \\
\hline 0 & 37,93 & 29,80 & 39,7 & 33,20 \\
\hline 110 & 44,73 & 36,83 & 48,75 & 37,87 \\
\hline \multirow[t]{2}{*}{220} & 53,53 & 42,17 & 49,6 & 41,10 \\
\hline & \multicolumn{2}{|c|}{ FLV } & \multicolumn{2}{|c|}{ FLV } \\
\hline \multicolumn{5}{|l|}{ Dose } \\
\hline 0 & 0,93 & 0,94 & 0,78 & 1,18 \\
\hline 110 & 0,75 & 0,82 & 0,66 & 0,87 \\
\hline \multirow[t]{2}{*}{220} & 0,93 & 0,63 & 0,74 & 0,97 \\
\hline & \multicolumn{2}{|c|}{ NBI } & \multicolumn{2}{|c|}{ NBI } \\
\hline \multicolumn{5}{|l|}{ Dose } \\
\hline 0 & 40,77 & 32,81 & 50,94 & 30,01 \\
\hline 110 & 59,67 & 43,53 & 74,42 & 42,79 \\
\hline 220 & 57,72 & 65,57 & 66,88 & 41,86 \\
\hline
\end{tabular}

Rev. Ceres, Viçosa, v. 65, n.3, p. 261-270, mai/jun, 2018 


\section{Efeito do Modo de Aplicação (Idade das Plantas 34, 42, 62 e 76 DAE)}

Os valores médios observados dos índices SPAD, CHL, FLV e NBI, em função do modo de aplicação do $\mathrm{N}(0 \%$, $50 \%+50 \%$ e $100 \%$ ), nas avaliações efetuadas em diferentes idades da planta $(34,42,62$ e 76 DAE), nos dois cultivares, Ágata e Asterix, estão na Tabela 3.

Em ambos os cultivares houve efeito significativo do modo de parcelamento da dose de $\mathrm{N}$, da idade da planta e da interação entre ambos sobre os índices SPAD, CHL, FLV e NBI.

Também, para ambos os cultivares, os valores de SPAD, CHL e NBI decresceram com a idade da planta e o oposto ocorreu com o índice FLV (Figuras 1 e 2). O decréscimo dos índices indica que a cor verde da folha da batata, de ambos os cultivares, vai se tornando menos intensa à medida que a idade da planta avança. É neste período que a tuberização é intensificada. Fotoassimilados e nutrientes são direcionados para os tubérculos, e as folhas, com o passar dos dias, começam a senescer sendo perceptível primeiramente nos tratamentos que sofreram estresse ou falta de N.
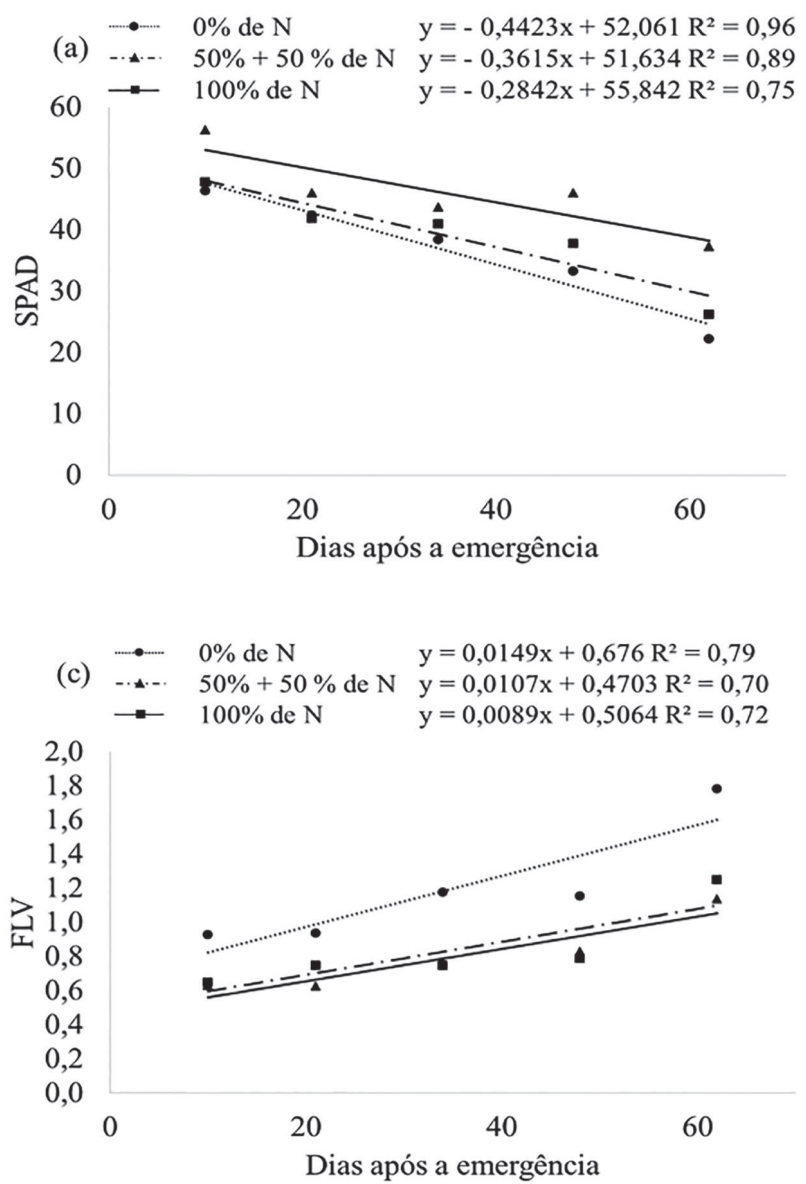

Consequentemente, ambos os cultivares manifestaram deficiência de $\mathrm{N}$ por meios desse indicador nutricional, no controle. Isto indicou que a disponibilidade de $\mathrm{N}$ no solo não foi suficiente para satisfazer as exigências da cultura. O N está presente na estrutura da molécula de clorofila; no entanto, quantidade insuficiente de clorofila resultará em clorose das folhas. O índice de CHL apresentou-se menor no tratamento controle.

\section{Correlação entre os índices e a produtividade final}

A relação entre os índices SPAD, CHL, FLV e NBI com a produtividade de tubérculos de batata, na colheita final, para os dois cultivares, está apresentada na Tabela 4.

Com diferentes idades da planta, a relação entre as leituras dos índices SPAD e CHL, na quarta folha da batata, e a produtividade de tubérculos, foi positiva para ambos os cultivares, indicando que o teor de clorofila na folha está correlacionada com a produtividade (Tabela 4). Esses resultados indicam que tanto o índice SPAD quanto o índice CHL podem propiciar índice de prognóstico da produtividade. Entretanto, a medição do índice SPAD é feita com equipamento de menor custo.
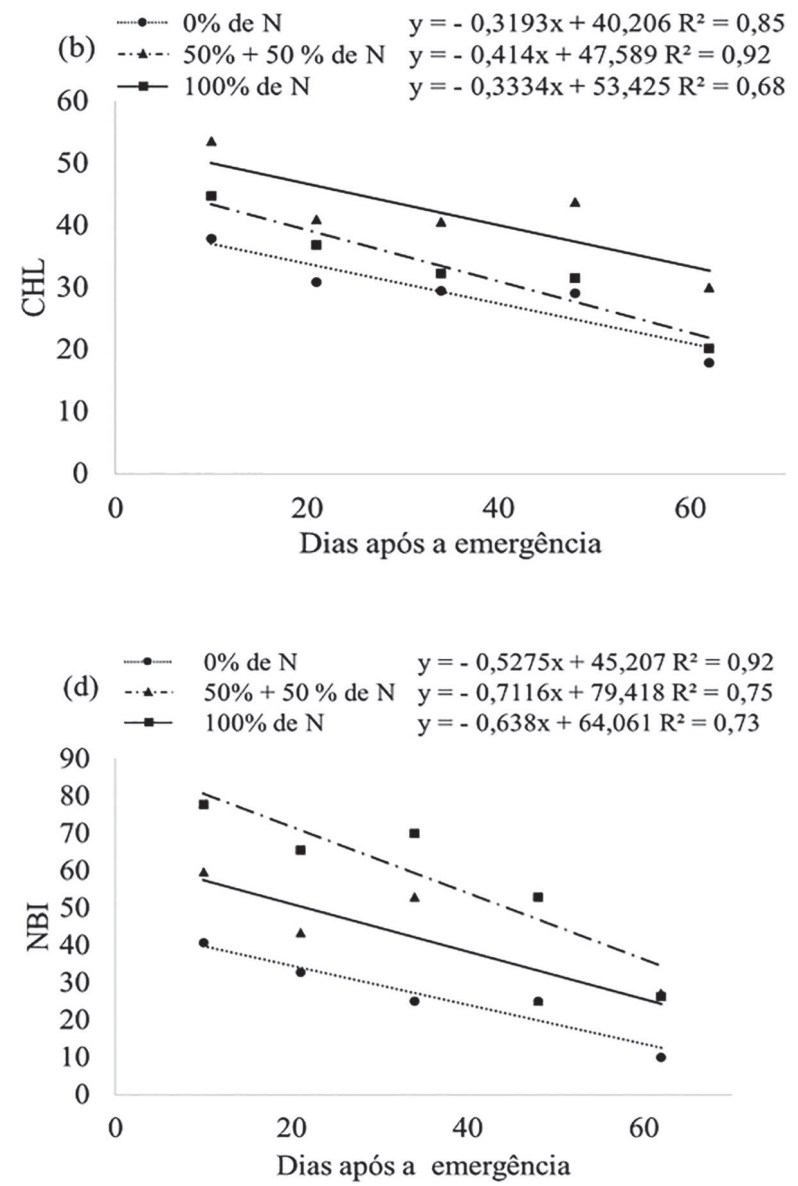

Figura 1: Relação dos índices SPAD (a), CHL (b), NBI (c) e FLV (d), medidos com o Dualex, ao longo do desenvolvimento do cultivar Ágata. 
Os efeitos da interação entre o índice FLV e a produtividade não foram significativos, aos 10, 48, 68 e 10, 76, para os cultivares Ágata e Asterix, respectivamente. A interação também não foi significativa para o índice NBI e a produtividade, aos 10 e 62, para o cultivar Ágata. Para o cultivar Asterix, houve relação significativa entre o índice NBI e a produtividade.

A diagnose precoce em tempo real é importante, pois possibilita tomar decisões sobre a aplicação de N em cobertura, com menor probabilidade de comprometimento da produção. Coelho et al. (2012a) encontraram correlação entre os índices avaliados com o Dualex e a produtividade comercial de tubérculos de batata. Tremblay et al. (2010) encontraram correlação positiva entre a produtividade de trigo e as leituras realizadas pelo Dualex, sendo que a relação CHL/FLV foi a variável que melhor se correlacionou com a produtividade.

$\mathrm{Na}$ literatura, há trabalhos em que são correlacionados os valores do índice SPAD e a produção de tubérculos de batata (Gil et al., 2002; Coelho et al., 2010). Assim, Coelho et al. (2010) obtiveram correlação linear positiva entre índice SPAD, teor de teor de clorofila e teor de $\mathrm{N}$ na matéria seca da folha, com a produção comercial de tubérculos de batata. Também, Gil et al. (2002) encontraram correlação positiva entre o valor do índice SPAD e a produção. Por essa razão, o índice SPAD talvez possa ser usado com precisão no prognóstico da produtividade das culturas visto que mede a intensidade de verde da folha, que está relacionado com o teor de clorofila e com a taxa fotossintética da planta (Fontes, 2011). Aumento da taxa fotossintética da planta pode estar associado com o aumento da produção das plantas. Assim, foram encontradas correlações positivas entre o valor do índice SPAD e a produção de grãos de milho (Piekielek \& Fox, 1992), feijão (Stone et al., 2002) e trigo (Monostori et al., 2016). Os últimos autores indicam que a relação entre o valor índice SPAD e a produção de trigo deve ser calibrado para cada cultivar, pois características das folhas e condições ambientais influenciam a medição com o índice SPAD.

\section{Modelos para o prognóstico}

Na cultura da batata, é o tubérculo que tem valor econômico. Além de ser específica para cada cultivar, a relação entre o índice SPAD e a produtividade de tubérculos
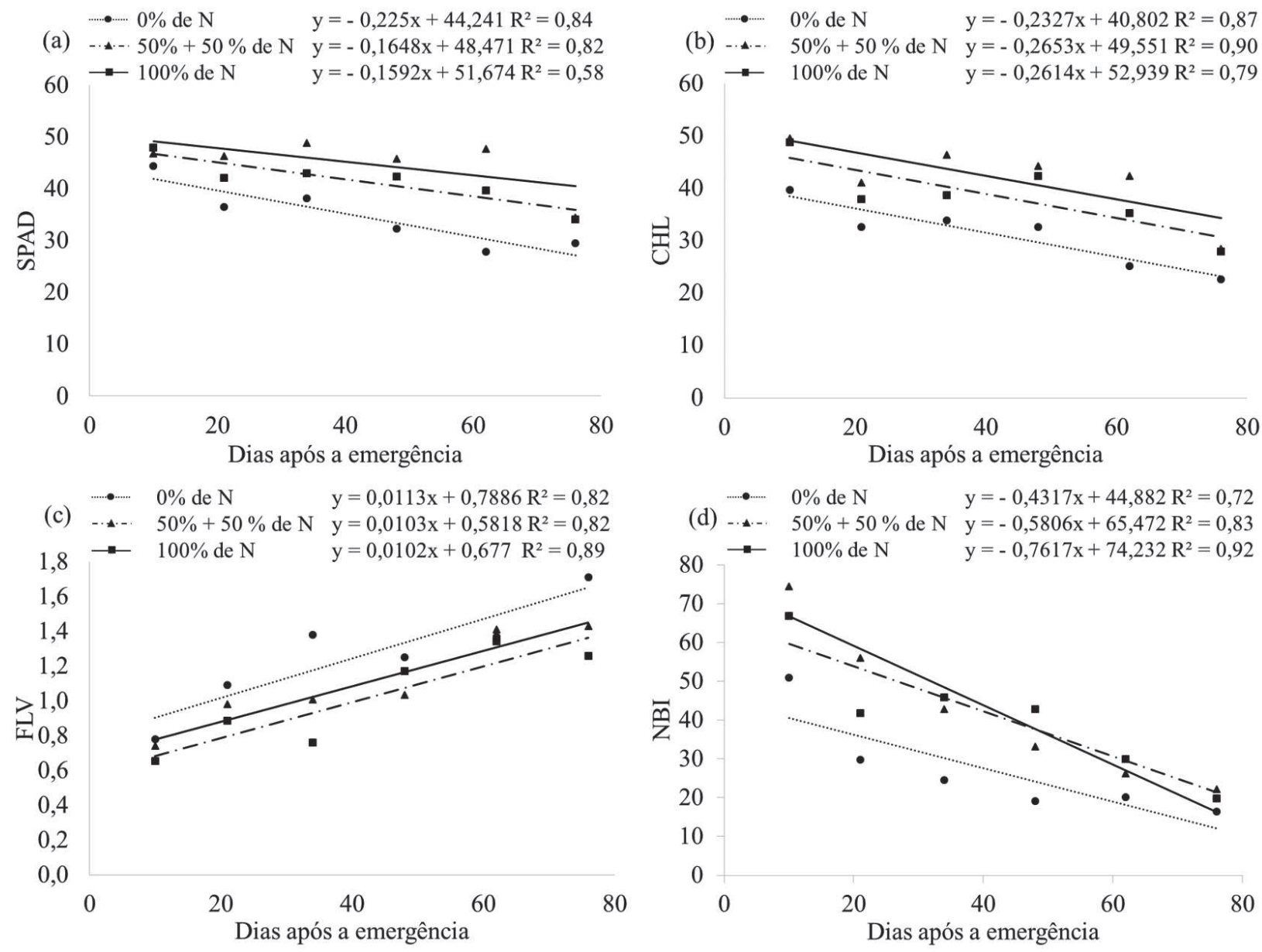

Figura 2: Relação dos índices SPAD (a), clorofila (CHL b), índice balanço de N (NBI c) e flavonoides (FLV d), medidos com o Dualex, ao longo do desenvolvimento do cultivar Asterix.

Rev. Ceres, Viçosa, v. 65, n.3, p. 261-270, mai/jun, 2018 
necessita considerar diferentes idades das plantas. Assim, os modelos para o prognóstico da produtividade total de tubérculos, com base nas leituras SPAD, efetuadas em diferentes idades da planta de batata, para os cultivares Ágata e Asterix, estão na Tabela 5. A predição da produtividade de batata, com base na leitura SPAD, é fortalecida pela forte relação existente entre o suprimento de $\mathrm{N}$, a concentração de clorofila nas folhas e a leitura SPAD, principalmente em ambiente onde o $\mathrm{N}$ é o fator mais limitante da produção. Embora modelos com maior número de variáveis, normalmente difíceis de serem obtidas, possam proporcionar maior precisão, os modelos propostos, com única avaliação, podem propiciar aceitável estimativa da produtividade da cultura da batata.

Tabela 2: Coeficientes de correlação linear entre os índices SPAD, clorofila (CHL), índice balanço de N (NBI) e flavonoides (FLV) e as características representativas do estado de $\mathrm{N}$ da planta, teor de $\mathrm{N}$ na seiva do pecíolo (TNSP), teor de $\mathrm{N}$ da matéria seca (TNMS) e quantidade de $\mathrm{N}$ acumulada da matéria seca (QNA) da quarta folha da batata, determinados aos 10 e 21 dias após a emergência (DAE), para os cultivares Ágata e Asterix

\begin{tabular}{|c|c|c|c|c|c|c|}
\hline \multirow{3}{*}{ Índices } & \multicolumn{5}{|c|}{ Características representativas do estado de $\mathbf{N}$} & \multirow[b]{2}{*}{ QNA } \\
\hline & TNSP & TNMS & QNA & TNSP & TNMS & \\
\hline & \multicolumn{3}{|c|}{ Ágata } & \multicolumn{3}{|c|}{ Asterix } \\
\hline \multicolumn{7}{|c|}{ Aos $10 \mathrm{DAE}$} \\
\hline SPAD & 0,64 & $0,78^{*}$ & $0,97 * *$ & 0,62 & $0,79 *$ & $0,88^{* *}$ \\
\hline Dualex - CHL & $0,83 * *$ & $0,94 * *$ & $0,96 * *$ & $0,87 * *$ & $0,97 * *$ & $0,77 *$ \\
\hline Dualex - FLV & $-0,44$ & $-0,11$ & $-0,24$ & $-0,22$ & $-0,59$ & $-0,93 * *$ \\
\hline Dualex - NBI & $0,96 * *$ & $0,84 * *$ & 0,63 & 0,61 & $0,87 * *$ & $0,94 * *$ \\
\hline \multicolumn{7}{|c|}{ Aos 21 DAE } \\
\hline SPAD & 0,51 & 0,37 & 0,61 & $0,94 * *$ & $0,97 * *$ & $0,91 * *$ \\
\hline Dualex - CHL & $0,99 * *$ & $0,95 * *$ & $0,83 * *$ & $0,92 * *$ & $0,97 * *$ & $0,91 * *$ \\
\hline Dualex - FLV & $-0,91 * *$ & $-0,84 * *$ & $-0,66$ & $-0,36$ & $-0,62$ & $-0,78^{*}$ \\
\hline Dualex - NBI & $0,93 * *$ & $0,86^{* *}$ & $0,68^{*}$ & $0,72 *$ & $0,90 * *$ & $0,97 * *$ \\
\hline
\end{tabular}

** $\mathrm{e} *$ significativos a 1 e $5 \%$ de probabilidade, respectivamente.

Tabela 3: Valores dos índices SPAD, clorofila (CHL), flavonoides (FLV) e índice balanço de N (NBI), em função do modo de parcelamento do nitrogênio (0, 50/50 e 100), em diferentes idades da planta de batata (34, 48, 62 e 76 DAE), cultivares Ágata e Asterix

\begin{tabular}{|c|c|c|c|c|c|c|c|}
\hline \multicolumn{8}{|c|}{ DAE } \\
\hline & 34 & 48 & 62 & 34 & 48 & 62 & 76 \\
\hline & \multicolumn{3}{|c|}{ Ágata } & \multicolumn{4}{|c|}{ Asterix } \\
\hline & & SPAD & & \multicolumn{4}{|c|}{ SPAD } \\
\hline \multicolumn{8}{|l|}{ Modo } \\
\hline 0 & 38,50 & 33,25 & 22,25 & 38,15 & 32,35 & 27,90 & 29,58 \\
\hline $50 / 50$ & 41,05 & 37,80 & 26,30 & 43,05 & 42,33 & 39,77 & 34,13 \\
\hline \multirow[t]{2}{*}{100} & 43,73 & 42,05 & 37,35 & 48,87 & 45,80 & 47,70 & 34,53 \\
\hline & \multicolumn{3}{|c|}{ CHL } & \multicolumn{4}{|c|}{ CHL } \\
\hline \multicolumn{8}{|l|}{ Modo } \\
\hline 0 & 29,45 & 29,05 & 17,87 & 33,80 & 32,60 & 25,15 & 22,60 \\
\hline $50 / 50$ & 32,23 & 31,55 & 20,15 & 38,65 & 42,30 & 35,27 & 27,87 \\
\hline \multirow[t]{2}{*}{100} & 40,55 & 43,75 & 30,00 & 46,35 & 44,30 & 42,30 & 28,37 \\
\hline & \multicolumn{3}{|c|}{ FLV } & \multicolumn{4}{|c|}{ FLV } \\
\hline \multicolumn{8}{|l|}{ Modo } \\
\hline 0 & 1,18 & 1,16 & 1,78 & 1,38 & 1,71 & 1,25 & 1,37 \\
\hline $50 / 50$ & 1,28 & 0,59 & 0,75 & 1,17 & 0,76 & 1,34 & 1,26 \\
\hline \multirow[t]{2}{*}{100} & 0,76 & 0,63 & 1,14 & 1,01 & 1,04 & 1,41 & 1,43 \\
\hline & \multicolumn{3}{|c|}{ NBI } & \multicolumn{4}{|c|}{ NBI } \\
\hline \multicolumn{8}{|l|}{ Modo } \\
\hline 0 & 25,01 & 25,09 & 10,02 & 24,50 & 19,10 & 20,12 & 16,50 \\
\hline $50 / 50$ & 25,10 & 53,51 & 27,06 & 33,20 & 56,12 & 26,28 & 22,11 \\
\hline 100 & 53,03 & 70,01 & 26,31 & 45,90 & 42,83 & 29,95 & 19,85 \\
\hline
\end{tabular}


Em outra situação experimental, com base na leitura SPAD, o modelo proposto para estimar a produtividade comercial de tubérculos (PC) do cultivar Asterix, em t/ha, foi $\mathrm{PC}=13,74+0,53 \mathrm{SPAD}$ (Fontes et al., 2016). Modelos para estimar a produtividade das culturas, com base na leitura SPAD, têm sido propostos (Le Bail et al., 2005; Yildirim et al., 2010; Islam et al., 2014). Variação da leitura do medidor SPAD, por diversos fatores, como época do

Tabela 4: Coeficientes de correlação linear entre os índices SPAD, clorofila (CHL), índice balanço de N (NBI) e flavonoides (FLV), determinados aos 10, 21, 34, 48, 62 e 76 dias após a emergência das plantas (DAE) e produtividade de tubérculos na colheita final, cultivares Ágata e Asterix

\begin{tabular}{|c|c|c|c|c|}
\hline \multirow{2}{*}{$\begin{array}{l}\text { Idade da planta } \\
\text { DAE }\end{array}$} & \multicolumn{4}{|c|}{ Índices } \\
\hline & SPAD & CHL & FLV & NBI \\
\hline 10 DAE - Ágata & $0,84 * *$ & $0,77^{*}$ & $-0,26$ & 0,47 \\
\hline 10 DAE - Asterix & $0,79^{*}$ & $0,94 * *$ & $-0,63$ & $0,88 * *$ \\
\hline 21 DAE - Ágata & $0,77^{*}$ & $0,78^{*}$ & $-0,79 *$ & $0,79 *$ \\
\hline $21 \mathrm{DAE}$ - Asterix & $0,82 * *$ & $0,81 * *$ & $-0,77 *$ & $0,90 * *$ \\
\hline 34 DAE - Ágata & $0,77 *$ & $0,77 *$ & $-0,75^{*}$ & $0,77 *$ \\
\hline 34 DAE - Asterix & $0,82 * *$ & $0,76^{*}$ & $-0,87 * *$ & $0,77^{*}$ \\
\hline 48 DAE - Ágata & $0,80 * *$ & $0,85^{* *}$ & $-0,51$ & $0,75^{*}$ \\
\hline 48 DAE - Asterix & $0,90 * *$ & $0,94 * *$ & $-0,91 * *$ & $0,89 * *$ \\
\hline 62 DAE - Ágata & $0,81 * *$ & $0,81 * *$ & $-0,27$ & 0,51 \\
\hline 62 DAE - Asterix & $0,87 * *$ & $0,87 * *$ & $0,76^{*}$ & $0,90 * *$ \\
\hline 76 DAE - Ágata & - & - & - & - \\
\hline 76 DAE - Asterix & $-0,89 * *$ & $-0,93 * *$ & $--0,14$ & $-0,88 * *$ \\
\hline
\end{tabular}

** e *, significativos a 1 e $5 \%$ de probabilidade, respectivamente

Tabela 5: Modelos para o prognóstico da produtividade total de tubérculos na colheita final (Y, em g/planta), com base nas leituras SPAD e índice balanço de N (NBI) efetuadas em diferentes idades da planta de batata (10, 21, 34, 48, 62 e 76 dias após a emergência), cultivares Ágata e Asterix

\begin{tabular}{|c|c|c|}
\hline DAE & Modelo & $\mathbf{R}^{2}$ \\
\hline & Ágata & \\
\hline \multirow{2}{*}{10} & $Y=-1463+51,5$ SPAD & 0,71 \\
\hline & $\mathrm{Y}={ }^{\mathrm{NS}} \mathrm{NBI}$ & - \\
\hline \multirow{2}{*}{21} & $\mathrm{Y}=-3361+103,1 \mathrm{SPAD}$ & 0,60 \\
\hline & $Y=381+15,6 \mathrm{NBI}$ & 0,63 \\
\hline \multirow{2}{*}{34} & $Y=-2460+87,2$ SPAD & 0,60 \\
\hline & $\mathrm{Y}=581+15,7 \mathrm{NBI}$ & 0,59 \\
\hline \multirow{2}{*}{48} & $Y=-459+40,5$ SPAD & 0,64 \\
\hline & $\mathrm{Y}=578+11,0 \mathrm{NBI}$ & 0,57 \\
\hline \multirow{3}{*}{62} & $\mathrm{Y}=149+34,0 \mathrm{SPAD}$ & 0,65 \\
\hline & $\mathrm{Y}={ }^{\mathrm{NS}} \mathrm{NBI}$ & - \\
\hline & Asterix & \\
\hline \multirow{2}{*}{10} & $Y=-4845+131,7$ SPAD & 0,62 \\
\hline & $\mathrm{Y}=-258+23,8 \mathrm{NBI}$ & 0,78 \\
\hline \multirow{2}{*}{21} & $Y=-986+54,1$ SPAD & 0,68 \\
\hline & $Y=-260+40,0 \mathrm{NBI}$ & 0,81 \\
\hline \multirow{2}{*}{34} & $Y=-895+49,9$ SPAD & 0,67 \\
\hline & $\mathrm{Y}=457+23,5 \mathrm{NBI}$ & 0,60 \\
\hline \multirow{2}{*}{48} & $Y=-429,7+42,3$ SPAD & 0,82 \\
\hline & $\mathrm{Y}=655+15,6 \mathrm{NBI}$ & 0,80 \\
\hline \multirow{2}{*}{62} & $Y=164+28,7$ SPAD & 0,76 \\
\hline & $Y=-237+59,2 \mathrm{NBI}$ & 0,81 \\
\hline \multirow{2}{*}{76} & $Y=-1661+89,5$ SPAD & 0,80 \\
\hline & $Y=-634+97,7 \mathrm{NBI}$ & 0,78 \\
\hline
\end{tabular}

Rev. Ceres, Viçosa, v. 65, n.3, p. 261-270, mai/jun, 2018 
ano, estádio de desenvolvimento da planta, ambientes, cultivares, manejo, entre outros, sinaliza para a não generalização e a necessidade do ajuste local do modelo.

Os modelos ajustados podem ter importância em diversas atividades, como em programas de melhoramento, em seleção precoce de plântula; em planejamento de medidas gerenciais da propriedade; na organização sazonal da colheita e da comercialização; na geração de algoritmos visando a estimar a dose de fertilizante nitrogenado a aplicar em cobertura, dentre outros (Fontes, 2016).

\section{CONCLUSÕES}

As doses e o parcelamento de $\mathrm{N}$ interferem nos índices avaliados, sendo que os valores dos índices SPAD, CHL e NBI decrescem com a idade da planta e o oposto ocorre com o índice FLV, para ambos os cultivares.

O índice CHL é o mais indicado para estimar indiretamente o teor de nitrato da seiva do pecíolo, teor de $\mathrm{N}$ da matéria seca e quantidade de $\mathrm{N}$ acumulada da quarta folha.

Tanto o índice SPAD quanto o índice CHL podem prognosticar a produtividade final de tubérculos de batata.

\section{AGRADECIMENTOS}

Os autores agradecem ao Conselho Nacional de Desenvolvimento Científico (CNPq) e Tecnológico e à Fundação de Amparo à Pesquisa do Estado de Minas Gerais (FAPEMIG) pelo apoio financeiro.

\section{REFERÊNCIAS}

Baránková B, Lazar D \& Naus J (2016) Analysis of the effect of chloroplast arrangement on optical properties of green tobacco leaves. Remote Sensing of Environment, 174:181-196.

Cardoso AD, Alvarenga MAR, Melo TL \& Viana AES (2007) Produtividade e qualidade de tubérculos de batata em função de doses e parcelamento de nitrogênio e potássio. Revista Ciência e Agrotecnologia, 31:1729-1736.

Cartelat A, Cerovic ZG, Goulas Y, Meyer S, Lelarge C, Prioul JL, Barbottin A, Jeuffroy MH, Gate P, Agati G \& Moya I (2005) Optically assessed contents of leaf polyphenolics and chlorophyll as indicators of nitrogen deficiency in wheat (Triticum aestivum L.). Field Crops Research, 91:35-49.

Coelho FS, Fontes PCR, Finger FL \& Cecon PR (2012a) Avaliação do estado nutricional do nitrogênio em batateira por meio de polifenóis e clorofila na folha. Pesquisa Agropecuária Brasileira, 47:584-592.

Coelho FS, Fontes PCR, Braun H \& Silva MCC (2012b) Using a chlorophyll meter readings for monitoring nitrogen status of potato cultivars. Journal of Agricultural Science and Technology, $2: 248-256$

Coelho FS, Fontes PCR, Puiatti M, Neves JCL \& Silva MCC (2010) Dose de nitrogênio associada à produtividade de batata e índices do estado de nitrogênio na folha. Revista Brasileira de Ciência do Solo, 34:1175-1183.
Demotes-Mainard S, Boumaza R, Meyer S \& Cerovic ZG (2008) Indicators of nitrogen status for ornamental woody plants based on optical measurements of leaf epidermal polyphenol and chlorophyll contents. Scientia Horticulturae, 115:377-385.

Fontes PCR (2016) Nutrição Mineral de Plantas: anamnese e diagnóstico. Viçosa, Editora UFV. 315 p.

Fontes PCR, Braun H, Silva MCC, Coelho FS, Cecon PR \& Partelli FL (2016) Tuber yield prognosis model and agronomic nitrogen use efficiency of potato cultivars. Australian Journal of Crops Science, 10:933-939.

Fontes PCR (2011) Nutrição mineral de plantas: avaliação e diagnose. Viçosa, Editora Arka. 296 p.

Fontes PCR (2001) Diagnóstico do estado nutricional das plantas. Viçosa, Editora UFV. 121 p.

Fortier E, Desjardins Y, Tremblay N, Bélec C \& Côté M (2010) Influence of irrigation and nitrogen fertilization on broccoli polyphenolics concentration. Acta Horticulturae, 856:55-62.

Gil PT, Fontes PCR, Cecon PR \& Ferreira FA (2002) Índice SPAD para o diagnóstico do estado de nitrogênio e para o prognóstico da produtividade de batata. Horticultura Brasileira, 20:611-615.

Giletto CM, Rattín JE, Díaz C, Echeverría HE \& Caldiz DO (2006) Evaluación de la nutrición nitrogenada en nuevas variedades de papa aptas para el procesamiento industrial. Ciencia del Suelo, 24:65-75.

Huan Y, Hua-Song W \& Zhi-Jie W (2010) Evaluation of SPAD and Dualex for in-season corn nitrogen status estimation. Acta Agronomica Sinica, 36:840-847.

Islam MR, Haque KS, Akter N \& Karim MA (2014) Leaf chlorophyll dynamics in wheat based on SPAD meter reading and its relationship with grain yield. Journal of Scientia Agriculture, 8:13-18.

Le Bail M, Jeuffroy MH, Bouchard C \& Barbottin A (2005) Is it possible to forecast the grain quality and yield of different varieties of winter wheat from Minolta SPAD meter measurements? European Journal of Agronomy, 23:379-391.

Li L, Qin Y, Liu Y, Hu Y \& Fan M (2012) Leaf Positions of potato suitable for determination of nitrogen content with a SPAD meter. Plant Production Science, 15:317-322.

Monostori I, Árendás T, Hoffman B, Galiba G, Gierczik K, Szira F \& Vágújfalvi A (2016) Relationship between SPAD value and grain yield can be affected by cultivar, environment and soil nitrogen content in wheat. Euphytica, 211:103-112.

Muñoz-Huerta RF, Guevara-Gonzalez RG, Contreras-Medina LM, Torres-Pacheco I, Prado-Olivarez J \& Ocampo-Velazquez RV (2013) A review of methods for sensing the nitrogen status in plants: advantages, disadvantages and recent advances. Sensors, 13:10823-10843.

Piekielek WP \& Fox RH (1992) Use of a chlorophyll meter to predict sidedress nitrogen requirements for maize. Agronomy Journal, 84:59-65.

Saravia D, Farfán-Vignolo ER, Gutiérrez R, Mendiburu F, Schafleitner R, Bonierbale M \& Khan MA (2016) Yield and physiological response of potatoes indicate different strategies to cope with drought stress and nitrogen fertilization. American Journal of Potato Research, 93:288-295.

SAS Institute Inc. (2002) Statistical Analysis System user's guide. Version 9.0. Cary, Statistical Analysis System Institute. 513p.

Schepers JS, Francis DD, Vigil M \& Below FE (1992) Comparison of corn leaf nitrogen concentration and chlorophyll meter readings. Communications in Soil Science and Plant Analysis, 23:2173-2187. 
Stone LF, Silva GME \& Moreira JAA (2002) Uso do clorofilômetro SPAD-502 na estimativa do nitrogênio foliar específico e da produtividade do feijoeiro. In: Congresso Nacional de Pesquisa de Feijão, Viçosa. Anais, Universidade Federal de Viçosa. p.743746.

Tremblay N, Wang Z \& Bélec C (2010) Performance of Dualex in spring wheat for crop nitrogen status assessment, yield prediction and estimation of soil nitrate content. Journal of Plant Nutrition, $33: 57-70$.

Xiong D, Chen J, Yu T, Gao W, Ling X, Li Y \& Huang J (2015) SPAD-based leaf nitrogen estimation is impacted by environmental factors and crop leaf characteristics. Scientific Reports, 5:01-12.
Yildirim M, Kiliç H, Kendal E \& Karahan T (2010) Applicability of chlorophyll meter readings as yield predictor in durum wheat. Journal of Plant Nutrition, 34:151-164.

Zakeri H, Schoenau J, Vandenberg A, Aligodarz MT \& Bueckert RA (2015) Indirect estimations of lentil leaf and plant $n$ by SPAD chlorophyll meter. International Journal of Agronomy, 2015:01-10.

Zheng H, Liu Y, Qin Y, Chen Y \& Fan M (2015) Establishing dynamic thresholds for potato nitrogen status diagnosis with SPAD chlorophyll meter. Journal of Integrative Agriculture, 14:190-195. 